\title{
ANALYSIS OF THE RISKS OF SMALL AND MEDIUM-SIZED ENTERPRISES IN THE ZILINA REGION
}

Small and medium-sized enterprises (SMES) are very sensitive to changes in the business environment which after a certain time are always reflected into quantitative characteristics of this sector. In 2013, we accomplished a statistical survey on current trends in the field of business risks for SMEs in selected regions of the Czech Republic and Slovakia. In this article we want to analyze the effects of selected risks of the survey with respect to the length of the small and medium-sized business enterprises in the Zilina region. SMEs should be aware of their risks, mainly due to their importance in the economic system of the Slovak Republic, which mostly lies in their inconsiderable share to create job positions in the region.

Keywords: Enterprise, risk, dependence, business environment

\section{Introduction}

Small and medium-sized enterprises (SMEs) have become an increasingly important component of economic development, representing a substantial proportion of national economies worldwide [1]. In this context, Henderson and Weiler indicate that SMEs can be characterized as a major engine of economic growth [2]

SMEs represent a strong economic potential for development in the Slovak Republic. The area of support of SMEs business is currently one of the key issues of further direction of our economy. Business in SMEs is mainly specific for its flexibility and possibility of faster adaptation to turbulent conditions of the market environment compared to large enterprises. From the quantitative point of view there are micro-enterprises, i.e., enterprises with the fewest employees $(0-9)$ that are currently the most developed in Slovakia. Micro, small and medium-sized enterprises can be regarded as the driving force of national economies, as they create favorable conditions for increasing employment, the realization of innovative processes, but also create a suitable social environment in the regions [3]. Their flexibility predisposes to become a regional stabilization factor, even at the moment, at a time of increasing competitive pressures.

\section{Defining the problem}

\subsection{Current state of the business environment in the Zilina region in Slovakia}

In 2012, the economy of the Slovak Republic achieved growth in gross domestic product indicating the overall positive development in the economy. However, in the case of SMEs, the situation was different. Economic activity continued to decline and the trend towards marginalization of enterprises strengthened (business transfer from higher size categories into the category of micro-enterprises) resulting in a decrease in the number of enterprises with more than 10 employees to about half compared to 2008 [4].

In Slovakia, natural persons formed $70.2 \%$ and legal entities $29.8 \%$ out of a total number of SMEs in 2012 (551 608). Selfemployed persons $(92.8 \%)$ had the dominant representation in the context of natural persons. According to the data from the Register of Statistical Office SR [5] most of self-employed persons in 2012 worked in the Bratislava (15.2\%), Zilina (15.1\%) and Presov region (14.7\%).

There were registered 15167 active SMEs - legal entities (LE) in total in the Register of Statistical Office SR [6] in the Zilina region on 31.12 .2012 which was more by 1174 (8.4\%) subjects year-on-year. In terms of size:

\footnotetext{
* ${ }^{1}$ Maria Hudakova, ${ }^{2}$ Katarina Buganova, ${ }^{3}$ Jan Dvorsky, ${ }^{4}$ Jaroslav Belas, ${ }^{5}$ Leo-Paul Dana

${ }^{1}$ Faculty of Security Engineering, University of Zilina, Department of Crisis Management, Slovakia

${ }^{2}$ Faculty of Security Engineering, University of Zilina, Department of Crisis Management, Slovakia

${ }^{3}$ Faculty of Security Engineering, University of Zilina, Department of Crisis Management, Slovakia

${ }^{4}$ Faculty of Management and Economics, Tomas Bata University of Zlin, Department of Enterprise Economics, Czech Republic

${ }^{5}$ Faculty of Business and Economics, GSCM Montpelier Business School, France

E-mail: maria.hudakova@fbi.uniza.sk
} 
- micro-enterprises represented share of $89.5 \%$,

- small enterprises (10 - 49) represented share of $8.1 \%$,

- medium-sized enterprises (50 - 249) represented share of $2.0 \%$,

- large enterprises (250 - more) represented share of $0.4 \%$.

In the structure of SMEs (LE) and according to the type of economic activity, there were business entities prevailing in the area of trade $-37.4 \%$ (about 7.5 p.b. more than SR in total), commercial services $-19.0 \%$ (about $12.3 \%$ less than SR in total) and industry $-11.4 \%$.

\subsection{Management of business risks in Slovakia}

The need for more active and systematic engagement with risk rises in current changing business environment in Slovakia. Business risks arise from negative changes in internal and external business environment for SMEs. Currently, very wide range of business risks has effect on the SME which can not be clearly defined [7]. Every business is unique and so we must approach it in identifying potential risks that may endanger the business.

Small and medium-sized entrepreneur can create good conditions for risk management, as he is in close proximity to all aspects of individual operations and knows many strengths as well as the vulnerability of his business. On the other hand, even the owners of small and medium-sized enterprises are intuitively aware of common resources of risks that affect their daily lives [8]. Entrepreneurs are not always aware of such resources of risks as they do not have direct experience. Business experience in risk management often arises precisely of how long the entrepreneur carries out his business activities and thus sometimes can, sometimes cannot predict negative changes in the business environment [9].

SMEs are also much more closely tied to the region in which they implement their activities than large enterprises. In addition the enterprise is located in the region; its activity also participates in increasing regional employment and also brings other benefits to the region apart from economic benefits. Therefore, we focused on the quantitative analysis of selected risks of SMEs in this article from the point of view of their length of business in the Zilina region in Slovakia.

\section{Objective and procedure of problem solving}

In 2013, we accomplished a statistical survey of the business risks of SMEs in Zilina, within the project FaME/2013/MSPRISK: "Current trends in the area of business risks of small and mediumsized enterprises in selected regions of the Czech Republic and Slovakia." The project co-operated with Tomas Bata University in Zlin, Pan European University in Bratislava, University of Zilina and Trencin.
164 small and medium-sized enterprises in the region were surveyed. The structure of enterprises was as follows: $17 \%$ do business in production, $21 \%$ in commercial activities, $17 \%$ in construction enterprises, $6 \%$ in transport enterprises, $1 \%$ in agricultural enterprises and $38 \%$ formed the largest share of enterprises that do business in other sectors (trade, consulting, distribution, etc.).

In terms of the structure of SMEs and number of employees the results of the survey were as follows: $66 \%$ of micro-enterprises, $20 \%$ of small enterprises, $14 \%$ of medium-sized enterprises.

SMEs surveyed in the Zilina region: $38 \%$ do business more than 10 years, $32 \%$ do business from 5 to 10 years, $30 \%$ do business from 1 to 5 years.

The objective of article is based on data from a statistical survey to analyze the effect of selected risks to SMEs with regard to their length of business in the region. The length of business is an important factor affecting the perception of the business risks and their management style mostly. It is based on business experience of SME's owners, managers and their attitude to risk and their ability to manage risk as well.

In order to meet the objective stated, we used empirical research methods (questionnaire, interviews with competent persons of SMEs), statistical methods, i.e., analysis of variance using quantitative tools of statistics (percentages, averages, homoscedasticity, Bartlett's Test, Kolmogorov-Smirnov Test, F-test, Kruskal-Wallis Test, Box-and-Whisker Plot) and statistical software Statgraphics Centurion XV [10].

In our research, we focused on the market, financial, personnel, operational (production), security, legal risks to SMEs. The percentage of identified key risks for SMEs in Zilina is shown in Fig. 1.

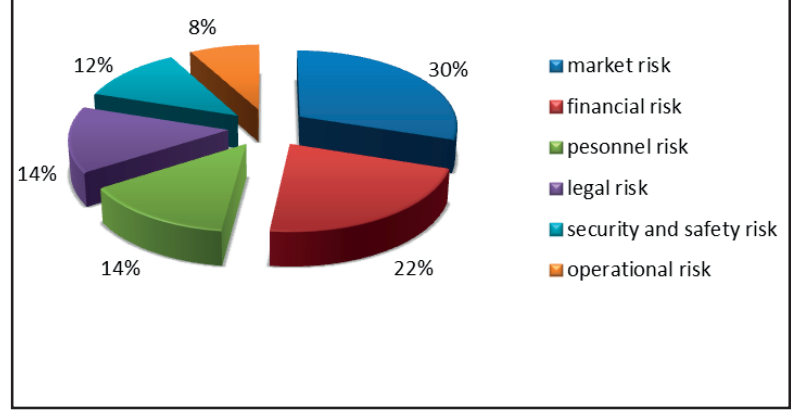

Fig. 1 Percentage of identified key risks for SMEs in the Zilina region

Subsequently were classified different intensities of identified key risks for SMEs, according to the length of their business in the region into three groups (Table 1).

Using statistical methods and tools we examined whether the average (mean) values of the key risks are dependent on the number of years of enterprise activities in the Zilina region or not. We used the quantitative method "analysis of variance". We 
Classification of key risks to SMEs according to the length of their business

Table 1

\begin{tabular}{|l|c|c|c|c|c|c|}
\hline $\begin{array}{l}\text { Key risks / SME groups according } \\
\text { to length of business }\end{array}$ & Market risk & Financial risk & Personnel risk & Legal risk & Security risk & Operational risk \\
\hline from 1 to 5 years & 40 & 24 & 14 & 18 & 17 & 12 \\
\hline from 5 to 10 years & 38 & 34 & 25 & 20 & 13 & 22 \\
\hline more than 10 years & 56 & 39 & 26 & 20 & 9 \\
\hline
\end{tabular}

Basic statistical characteristics of the key risks stated in three groups of SMEs according to the length of the business

Table 2

\begin{tabular}{|c|c|c|c|c|}
\hline Key risks & $\mathrm{BSCs}$ & SMEs from 1 to 5 years & SMEs from 5 to 10 years & SMEs more than 10 years \\
\hline \multirow{2}{*}{ Market risk } & $\mu$ & 58.28 & 48.90 & 50.77 \\
\hline & $\sigma$ & 21.73 & 17.19 & 18.69 \\
\hline \multirow{2}{*}{ Financial risk } & $\mu$ & 31.67 & 32.79 & 33.77 \\
\hline & $\sigma$ & 15.44 & 12.92 & 14.02 \\
\hline \multirow{2}{*}{ Operational risk } & $\mu$ & 25.00 & 31.46 & 26.44 \\
\hline & $\sigma$ & 14.92 & 11.41 & 9.81 \\
\hline \multirow[t]{3}{*}{ Personnel risk } & $\mu$ & 26.43 & 35.92 & 25.23 \\
\hline & $\sigma$ & 18.34 & 18.04 & 6.86 \\
\hline & $\sigma^{2}$ & 336.26 & 325.32 & 47.06 \\
\hline \multirow[t]{3}{*}{ Legal risk } & $\mu$ & 31.28 & 29.75 & 30.22 \\
\hline & $\sigma$ & 22.73 & 11.06 & 12.86 \\
\hline & $\sigma^{2}$ & 516.45 & 122.30 & 165.43 \\
\hline \multirow[t]{3}{*}{ Security risk } & $\mu$ & 28.00 & 25.63 & 23.05 \\
\hline & $\sigma$ & 24.43 & 12.89 & 8.36 \\
\hline & $\sigma^{2}$ & 597.0 & 166.2 & 59.8 \\
\hline
\end{tabular}

determined the analysis of variance either by parametric or nonparametric tests [11]. Using the calculation of parametric tests two basic conditions had to be met: the resulting p-value of the intensity of the key risks of the homoscedasticity test (identity of variances) and normality test to verify intensities of risks must be higher than the level of significance 0.05 we have chosen.

The necessary information for the analysis of variance is given in Table 2. The basic statistical characteristics (BSCs) are as follows: $\mu$ - average intensity of risk to the enterprise, $\sigma$ - standard deviation intensity of risk to the enterprise, $\sigma^{2}$ - variance intensity of risk to the enterprise.

\section{Results and discussion}

\subsection{Analysis of variance of SMEs' market risk}

High competition, price battle, customer behavior, all of these can cause failure of SMEs and loss of market share. Up to 134 of SMEs selected market risk among the three key risks in the current business, representing $81.7 \%$ of SMEs surveyed. For the use of the parametric test of the mean values of market risk in the three groups of SMEs according to the length of business in Zilina, the following conditions are as follows:

1. Homoscedasticity was fulfilled. Resulting p-value using the Bartlett's Test was 0.334 .

2. Normality of the risk intensity was fulfilled. The values of Kolmogorov-Smirnov Test found were as follows: p-value of business from 1 to 5 years is 0.207 , from 5 to 10 years is 0.534 , more than 10 years is 0.213 .

Table 3 shows that the resulting p-value of the analysis of the variance of market risk intensity for SMEs using parametric F-test is 0.071 . The value is higher than the level of significance 0.05 which was chosen. We can confirm that there are no statistically significant differences among variances of the intensity of market risk in individual groups of SMEs according to their length of business in the Zilina region on the level of the reliability of $95.0 \%$. The average values of the intensity of market risk do not depend on the length of the business activity on the market in the Zilina region. This fact corresponds well with the multiple Boxand-Whisker Plot in Fig. 2 where the red sign + represents the average intensity of market risk expressed as a percentage. 


\begin{tabular}{|c|c|c|c|c|c|}
\hline Variance of SMEs according to the length of the business & Sum of squares & Df & $\begin{array}{c}\text { Average of } \\
\text { squares }\end{array}$ & F-ratio & P-value \\
\hline Variance among groups of SMEs & 1995.9 & 2 & 997.948 & \multirow{3}{*}{2.69} & \multirow{3}{*}{0.0715} \\
\hline Variance within groups of SMEs & 48553.5 & 131 & 370.638 & & \\
\hline Total variance & 50549.4 & 133 & & & \\
\hline
\end{tabular}

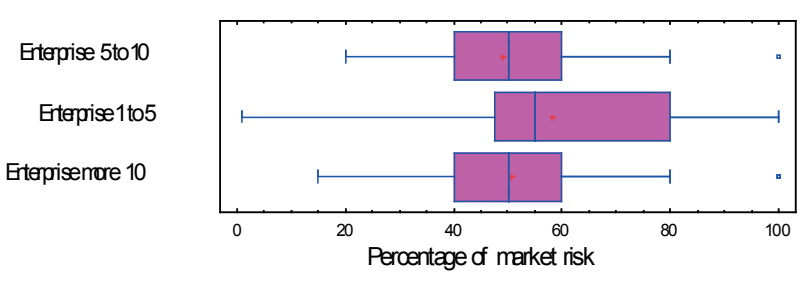

Fig. 2 Percentage of market risk using the Box-and-Whisker Plot

\subsection{Analysis of the variance of financial risk for SMEs}

The availability of financial resources, insolvency, enterprise debt and many other factors represent the financial risk for SMEs that was determined by $97 \%$ of the SMEs, $59.1 \%$ of SMEs surveyed. Considering the analysis of financial risk, parametric test of the mean values of financial risk in three groups of SMEs according to the length of the business in Zilina region could not be used, as all of the conditions were not fulfilled:

1. Homoscedasticity was fulfilled. Resulting p-value using the Bartlett's Test was 0.650 .

2. Normality of the risk intensity was not fulfilled. The $\mathrm{p}$-value was lower in one group of enterprises than the level of significance of 0.05 we had chosen. Kolmogorov-Smirnov Test detected the following values: p-value of enterprises business from 1 to 5 years is 0.032 , from 5 to 10 years is 0.487 , more than 10 years is 0.101 .

Subsequently, non-parametric multi-selective Kruskal-Wallis Test of medians of financial risk in defined groups of enterprises according to the length of the business in the region was performed. Since the calculated p-value of the analysis of intensity variance of financial risk from Table 4 is higher than 0.05 , we can say that there are no statistically significant differences among intensities of the financial risk medians of enterprise groups according to the length of the business in the region of Zilina with reliability of $95.0 \%$. Intensity of financial risk medians does not depend on the length of the SMEs on the market. This statement corresponds with multiple boxplot in Fig. 3 where the vertical blue lines represent the medians of the financial risk in the individual business groups expressed as a percentage.
Analysis of the variance of financial risk intensity using Kruskal-Wallis Test Table 4

\begin{tabular}{|l|c|c|l|}
\hline & $\begin{array}{l}\text { Number } \\
\text { of groups }\end{array}$ & $\begin{array}{l}\text { Financial } \\
\text { risk median }\end{array}$ & P-value \\
\hline Enterprise from 1 to 5 years & 24 & 44.2083 & \multirow{2}{*}{0.590038} \\
\hline Enterprise from 5 to 10 years & 34 & 49.4559 & \\
\hline Enterprise more than 10 years & 39 & 51.5513 & \\
\hline
\end{tabular}

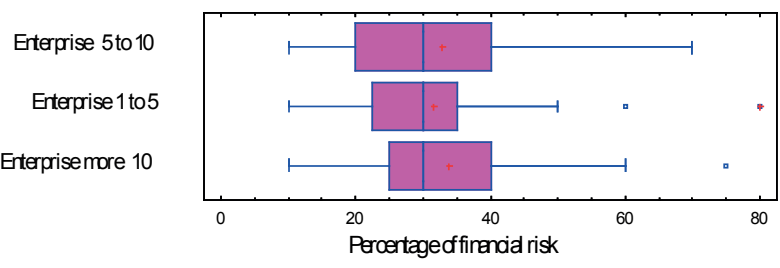

Fig. 3 Percentage of the financial risk using the Box-and-Whisker Plot

\subsection{Analysis of the variance of personnel, legal and security risk of SMEs}

The human factor has an indispensable role in SMEs, in terms of experience and knowledge in decision-making which may be benefit but also great risk for the enterprise. It is directly related to the risks arising from non-compliance with applicable legal standards, individual and public safety, as well as the safety of the products themselves, etc. When analyzing the personnel, legal and security risk, the course of calculating the analysis of variance was similar. Personnel risks were identified by 65 SMEs, representing $39.6 \%$ of the SMEs surveyed. Legal risk was identified by 60 SMEs, representing $36.6 \%$ and safety risk was identified by 53 SMEs, which is $32.3 \%$ of the SMEs surveyed. For the calculation of all these risks it was not possible to use parametric test of mean risk values in three risk groups of SMEs according to the length of the business in the Zilina region, since the first condition of homoscedasticity was not met. In all the cases, the resulting p-value was found by Bartlett's Test lower than the level of significance 0.05 which had been chosen:

- resulting p-value for the personnel risk was 0.00001 ,

- resulting $p$-value for the legal risk was 0.004 ,

- resulting p-value for the security risk was 0.0001 . 
Graphical display of the personnel risk of multiple boxplot in Fig. 4 shows that the length of the box (inner group variance) is for the enterprises with more than 10 years shorter than for other business groups. It is obvious even in the legal and security risk in Fig. 4 that the length of the box is for the enterprises with a length of business from 1 to 5 years longer than for other groups. Also the median of the group is about $7.5 \%$ smaller than the median of the remaining groups. On the basis of the graphical analysis and results of homoscedasticity test, we can say that the average (mean) values of the intensity of personnel, legal and security risk depend on the length of the enterprise activity on the market in the region and there are statistical differences among the groups of enterprises.

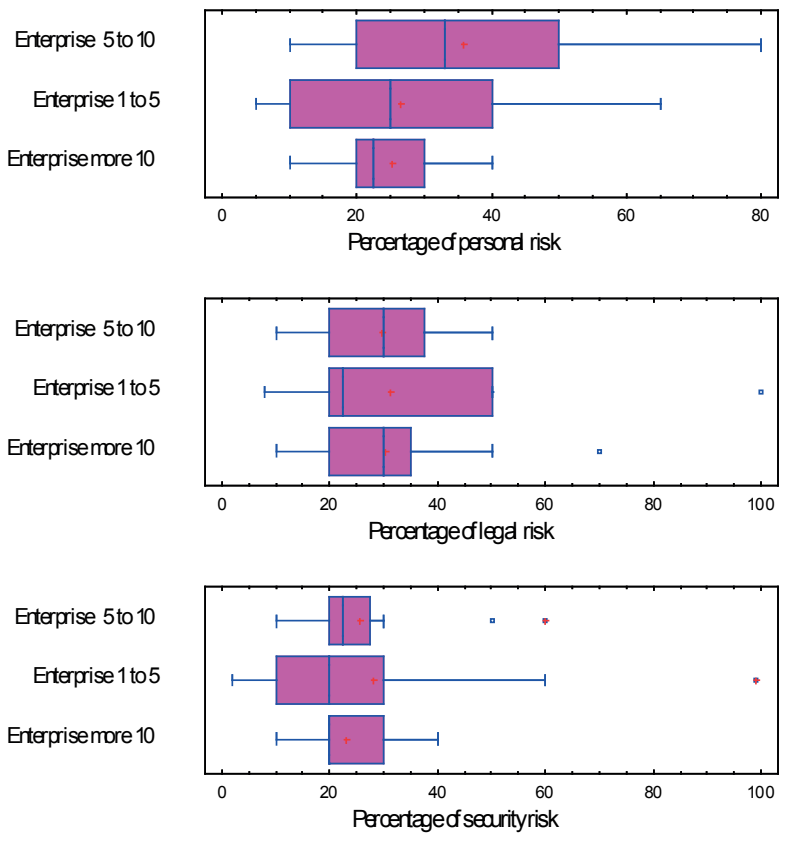

Fig. 4 Percentage of personnel, legal, security risks using Box-andWhisker Plot

\subsection{Analysis of variance of the operational risk of SMEs}

The production processes themselves, or provision of services and the implementation of outcomes in practice constitute resources of operational risk. Operational risk was identified only by 34 SMEs, representing $20.7 \%$ of the SMEs surveyed. For the use of the parametric test of the mean values of the operational risk in the three groups of SMEs according to the length of business in the region, the following conditions were fulfilled:

1. Homoscedasticity was fulfilled. Resulting p-value using the Bartlett's Test was 0.429 .

2. Normality of the risk intensity was fulfilled. The values of Kolmogorov-Smirnov Test found were as follows: p-value of enterprises with the business length from 1 to 5 years is 0.710 , from 5 to 10 years is 0.865 , more than 10 years is 0.363 .

The data from Table 5 shows that the resulting p-value of the analysis of the variance of operational risk intensity using parametric F-test is 0.408 . The value is higher than the level of significance of 0.05 we chose. We can confirm that there are no statistically significant differences among the variances of operational risk intensity in the various groups of SMEs according to their length of business in the region on the level of reliability of $95.0 \%$. The average values of the intensity of the operational risk do not depend on the length of enterprise activity on the market in the region. This statement corresponds with multiple boxplot in Fig. 5 where the red sign + represents the average intensity of market risk expressed as a percentage.

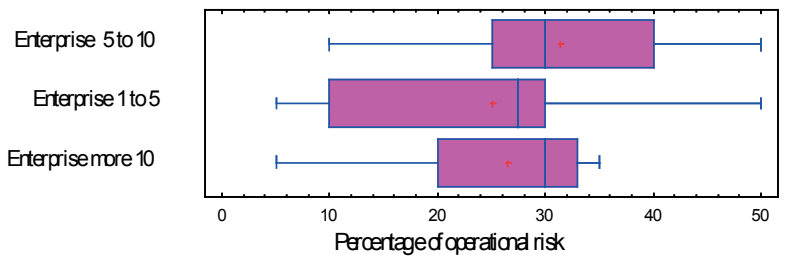

Fig. 5 Percentage of operational risk using the Box-and-Whisker Plot

\section{Conclusion}

The results from the analysis of the intensity of the key risks of SMEs identified with regard to their length of business in the Zilina region of Slovakia highlight the need to be prepared even more for unexpected changes to the current business environment. Using statistical methods and tools we were able to determine whether the average values of the key risks are dependent on the number of years of enterprise activities in the Zilina region or not. We applied quantitative method "ANOVA - analysis of variance". We calculated the analysis of variance either by parametric or non-parametric tests. Using the calculation of parametric tests two conditions had to be met:

Analysis of the variance of operational risk intensity using parametric F-test

Table 5

\begin{tabular}{|l|c|c|c|c|c|}
\hline Variance according to the length of the business & Sum of squares & Df & Average of square & F-ratio & P-value \\
\hline Variance among groups of SMEs & 284.812 & 2 & 142.406 & \multirow{3}{*}{0.92} & \multirow{2}{*}{0.4080} \\
\cline { 1 - 4 } Variance within groups of SMEs according to the length of business & 4783.45 & 31 & 154.305 & \multirow{2}{*}{5} & \\
\cline { 1 - 4 } Total variance & 5068.26 & 33 & & \\
\hline
\end{tabular}


the calculated p-value of the intensity of the key risks of the homoscedasticity test and normality test to verify intensities of risks must be higher than the level of significance 0.05 we have specified. The results of the above mentioned analysis of business risks for SMEs have confirmed that the intensity of market risk, financial risk, and operational risk is not dependent on the length of the enterprise activity on the market in the region. Therefore, many years of experience of managers often fail to protect SMEs before the unpredictable risks that the market economy and high competition can bring about.

The analysis and results of the tests showed that the personnel, legal and security risks depend on the length of the enterprise activity on the market in the Zilina region. In this case, the experience of the managers and owners prove beneficial. Assessing the risk, however, only on the basis of their own experience and feelings is currently inadequate. Therefore, the owners and managers of SMEs in Slovakia should rethink their approach to risk management.
It is necessary to increase the level of knowledge, in particular, enterprise owners (this is largely about microenterprises) about the possible causes and consequences of the risk, as well as on appropriate measures to be taken to reduce them. Improving the level of risk management in SMEs requires the acquisition of theoretical knowledge for the specific activities of the risk management process, methods and tools used in the management of risks. The absence of risk management can be one of the root causes of business failure and loss of competitive advantage especially in the highly unsettled business environment in Slovakia.

\section{Acknowledgements}

Publication of this paper was supported by the European Union within the project No. 26110230079 Innovation and internationalization of education - tools of quality enhancement of Zilina University in the European Education Area.

\section{Reference:}

[1] KARPAK, B., TOPCU, I.: Small Medium Manufacturing Enterprises in Turkey: An Analytic Network Process Framework for Prioritizing Factors Affecting Success. Intern. J. of Production Economics, 125: 60-70, ISSN 0925-5273.

[2] HENDERSON, J., WEILER, S.: Entrepreneurs and Job Growth: Probing the Boundaries of Time and Space, Economic Development Quarterly. 24(1): pp. 23-32, ISSN 0891-2424.

[3] HUtTmanova, E.: The Present State, Possibilities of Support and Development of Small and Medium-Size Enterprises in the Slovakia, [on line]. [cit. 2014-8-7], Available at: http://www.pulib.sk/elpub2/FM/Kotulic10/pdf_doc/11.pdf.

[4] SLOVAK BUSINESS AGENCY: Analysis and Surveys of Business Environment, [on line]. [cit. 2014-8-6], Available at: http:// www.sbagency.sk/sba-0

[5] Statistical Office of the Slovak Republic: Statistical Yearbook of the Regions of Slovakia 2013, [on line]. [cit. 2014-7-18], Available at: http://slovak.statistics.sk/.

[6] SMSP: Report on the State of Small and Medium-sized Enterprises in the Slovak Republic in the year 2012, [on line]. [cit. 2014-8-4], Available at: http://www.sbagency.sk/sites/default/files/file/stav_msp_2012u.pdf.

[7] HOLLA, K. et al.: Complex Model of Risk Assessment of Industrial Processes MOPORI. Communications - Scientific Letters of the University of Zilina, vol. 15, No. 2, pp. 63- 68, 2013, ISSN 1335-4205.

[8] RISTVEJ, J., ZAGORECKI, A.: Information Systems for Crisis Management - Current Applications and Future Directions, Communications - Scientific Letters of the University of Zilina, vol. 13, No. 2, pp. 59-63, 2011, ISSN 1335-4205.

[9] HUdAKOVA, M., BUGANOVA, K., LUSKOVA, M.: Small and Medium-Sized Enterprises Business Risks in Slovakia. WMSCI 2014: The $18^{\text {th }}$ World Multi-Conference on Systemics, Cybernetics and Informatics, Orlando : Florida, pp. 240-245, 2014, ISBN 13: 978-1-941763-05-6.

[10] STATGRAPHICS: SoftverStatgraphics Centurion XV. 2014, [on line]. [cit. 2014-7-11], Available at: http://www.statgraphics.com/ support/download_center.aspx

[11] BETAKOVA, J., ONDERISINOVA, K., MICHALKO, J., SUPAK, M.: Sustainable Development and Environmental Information Systems. Multimedia w organizacjach gospodarczych i edukacji, Warszawa : Difin, pp. 46-50, 2006, ISBN 83-7251-673-1. 